\title{
Ropivacaine at different concentrations on intrapartum fever, IL-6 and TNF- $\alpha$ in parturient with epidural labor analgesia
}

\author{
XIANJIN ZHOU $^{1 *}$, JIANG LI $^{1 *}$, SHENGQIONG DENG ${ }^{2}$, ZHENDONG XU $^{1}$ and ZHIQIANG LIU ${ }^{1}$ \\ ${ }^{1}$ Department of Anesthesiology, Shanghai First Maternity and Infant Hospital, \\ Tongji University School of Medicine, Shanghai 201204; ${ }^{2}$ Department of Laboratory, \\ Shanghai Gongli Hospital, The Second Military Medical University, Shanghai 200135, P.R. China
}

Received August 16, 2018; Accepted December 5, 2018

DOI: $10.3892 /$ etm.2018.7121

\begin{abstract}
Effects of ropivacaine at different concentrations on intrapartum fever, interleukin-6 (IL-6) and tumor necrosis factor- $\alpha(\mathrm{TNF}-\alpha)$ in parturient with epidural labor analgesia were compared to provide reference for the rational selection of anesthetics in clinic. Medical records of 198 cases of primiparas admitted to the Obstetrics and Gynecology Department, Shanghai First Maternity and Infant Hospital, Tongji University School of Medicine, from January 2017 to January 2018 were analyzed retrospectively and divided into 2 groups. A total of 105 patients were treated with $0.075 \%$ ropivacaine injection $10 \mathrm{ml}$ and $0.5 \mu \mathrm{g} / \mathrm{ml}$ sulfentanyl injection $100 \mathrm{ml}$ in parturition as the experimental group, and 93 patients were treated with $0.1 \%$ ropivacaine injection $10 \mathrm{ml}$ and $0.5 \mu \mathrm{g} / \mathrm{ml}$ sulfentanyl injection $100 \mathrm{ml}$ in parturition as the control group. After patient-controlled epidural analgesia, the pain visual analogue score (VAS), labor duration, administration time and febrile rate of parturient after administration were compared between the two groups at different time-points. Venous blood $2 \mathrm{ml}$ was taken at T1 (cervix open to $2 \mathrm{~cm}$ ), T2 (cervix fully open) and T3 (24 h postpartum), and the concentration of IL- 6 TNF- $\alpha$ was detected by enzyme-linked immunosorbent assay. The time of the second stage of labor and analgesia were shorter in the experimental group than that in the control group after administration $(\mathrm{P}<0.05)$. The febrile rate of parturient in the experimental group was lower than that in the control group $(\mathrm{P}<0.05)$. The concentration of IL-6 and TNF- $\alpha$ in the experimental group was lower than that in the control group at T2 $(\mathrm{P}<0.05 ; \mathrm{P}<0.01)$. The effect of patient-controlled epidural
\end{abstract}

Correspondence to: Dr Zhiqiang Liu, Department of Anesthesiology, Shanghai First Maternity and Infant Hospital, Tongji University School of Medicine, 2699 Gaoke West Road, Shanghai 201204, P.R. China

E-mail: q2592w@163.com; drliuzhiqiang@163.com

\section{${ }^{*}$ Contributed equally}

Key words: ropivacaine, epidural anesthesia, intrapartum fever, second stage labor time, IL-6, TNF- $\alpha$ administration with $0.075 \%$ ropivacaine injection combined with $0.5 \mathrm{mg} / \mathrm{ml}$ sulfentanyl injection on labor analgesia is shorter than that with $0.1 \%$ ropivacaine combined with sulfentanyl. It could also shorten the duration of the second stage of labor, reduce the intrapartum febrile rate, and alleviate inflammation.

\section{Introduction}

Childbirth is a natural physiological process that every parturient has to go through. Because of the physiological pain of labor, labor analgesia has been applied in clinic for many years, and is increasingly used by parturients (1). The labor analgesia technique of epidural anesthesia has been widely used in clinic in recent years because of its obvious analgesic effect, good safety and convenient operation, and has created good conditions for parturient labor (2). Studies have shown that in clinical anaesthesia, the lower the concentration of local anesthetic, the less likely patients are to develop adverse reactions, but at the same dosage, the duration of drug action is relatively shorter. Therefore, finding a suitable anesthetic concentration is of great significance in clinical application (3). Ropivacaine, as a long-acting amide local anesthetic with a single enantiomer, blocked the excitation and transmission of nerves by inhibiting the sodium channel of nerve cells. Ropivacaine can bind to proteins to form macromolecules, so it cannot pass through the placental barrier for the central nervous system, and has fewer toxic side effects on the central nervous system. In addition, it has little adverse effects on the fetus and it is a common anesthetic in clinical delivery (4). There have been few studies on the effects of labor analgesia on the physical environment of parturient. However, there are also reports that one of the effects of epidural analgesia on parturient is to increase the febrile rate of parturient, which has certain adverse effects on the delivery of parturient and the safety of mothers and infants (5), and intrapartum fever caused by epidural labor analgesia has become a hot topic in obstetrics (6,7). At present, the mechanism of fever in parturient during epidural analgesia is not very clear, but some studies have reported that fever is related to the thermotaxic center of parturient, but the most likely mechanism is inflammation (8).

Interleukin-6 (IL-6) and tumor necrosis factor- $\alpha$ (TNF- $\alpha$ ) are very important cytokines and cellular activity factors 
in parturition, which are closely related to the delivery process. It has been reported that IL-6 is not only closely related to pregnancy, but also plays a very important role in labor (9). IL-6 can increase the synthesis of prostaglandins and induce uterine contraction to initiate labor process. It is also a very important cell factor during the process of immune response and involved in inflammation (10). As an important inflammatory transmitter and immunomodulatory factor, TNF- $\alpha$ is produced by mononuclear macrophages, and its mechanism of labor facilitation during labor is similar to that of IL-6 (11). According to relevant reports, if epidural analgesia is used in labor, the level of IL-6 and TNF- $\alpha$ in maternal serum will increase significantly as analgesia time increases, and the IL-6 level in serum of febrile parturient is significantly higher than that of the non-febrile parturient (12). Therefore, some scholars believe that the increase in febrile rate during parturition may be due to the release of inflammatory factors caused by the use of extracellular analgesia (13).

In order to make a further demonstration of the above conclusion, this study explored the effects of ropivacaine at different concentrations on intrapartum fever, IL- 6 and TNF- $\alpha$ in the parturient with epidural labor analgesia.

\section{Materials and methods}

General materials. Medical records of 198 cases of primiparas admitted to Obstetrics and Gynecology Department in Shanghai First Maternity and Infant Hospital, Tongji University School of Medicine (Shanghai, China) from January 2017 to January 2018 were analyzed retrospectively and divided into 2 groups. A total of 105 patients were treated with $0.075 \%$ ropivacaine injection $10 \mathrm{ml}$ and $0.5 \mu \mathrm{g} / \mathrm{ml}$ sulfentanyl injection $100 \mathrm{ml}$ in parturition as the experimental group. The average age of the patients in the experimental group was $25.9 \pm 1.7$ years, the gestational age was $37-41$ weeks, the average gestational age was $39.3 \pm 0.5$ weeks, the body weight was $60.3 \pm 2.9 \mathrm{~kg}$, and the dilatation degree of cervix before analgesia was $1.9 \pm 0.4 \mathrm{~cm}$. A total of 93 patients were treated with $0.1 \%$ ropivacaine injection $10 \mathrm{ml}$ and $0.5 \mu \mathrm{g} / \mathrm{ml}$ sulfentanyl injection $100 \mathrm{ml}$ in parturition as the control group. The average age of the patients in the control group was $26.1 \pm 1.5$ years, the gestational age was $38-42$ weeks, the average gestational age was $38.9 \pm 0.7$ weeks, the body weight was $60.1 \pm 3.1 \mathrm{~kg}$, and the dilatation degree of cervix before analgesia was $2.0 \pm 0.6 \mathrm{~cm}$.

Inclusion and exclusion criteria. Inclusion criteria: all parturients were primiparas, full-term singletons and transvaginal pregnancies. Regular uterine contraction was $<10 \mathrm{~h}$, and labor analgesia by epidural anaesthesia was requested by primiparas themselves. Exclusion criteria: parturients with cardiopulmonary dysfunction, endocrine disease history, contraindications for epidural puncture, and body temperature higher than $37.5^{\circ} \mathrm{C}$ before analgesia were excluded. All parturients and their families signed an informed consent, and cooperated with the medical staff to complete the diagnosis and treatment. The study was approved by the Ethics Committee of Shanghai First Maternity and Infant Hospital, Tongji University School of Medicine.
Experimental reagents and instruments. Sodium lactate was purchased from Shanghai Baxter Medical Supplies Co., Ltd. (SFDA Approval no. H19993749; Shanghai, China). Ropivacaine was purchased from Jiangsu Hengrui Medicine Co., Ltd. (SFDA Approval no. H20060137; Jiangsu, China). Sulfentanyl was purchased from Yichang Renfu Pharmaceutical Co., Ltd. (SFDA Approval no. H20054256; Yichang, China). IL-6 (ELISA) kit and TNF- $\alpha$ (ELISA) kit were purchased from Shanghai Enzyme-linked Biotechnology Co., Ltd. (Shanghai, China).

Methods. Sodium lactate $8 \mathrm{ml} /(\mathrm{kg} / \mathrm{h})$ was injected after the establishment of upper limb intravenous access, upper fetal heart monitoring and ECG monitoring were conducted when two groups of parturient entered the labor room, and the temperature was adjusted to $23-25^{\circ} \mathrm{C}$. Epidural puncture was performed from the L2-3 space and the catheter was inserted into side of head, and the depth was about $3-4 \mathrm{~cm}$. 1.5\% lidocaine $3 \mathrm{ml}$ was injected into the body, if there was no adverse reaction after $5 \mathrm{~min}$, the catheter was fixed and connected to the patient-controlled epidural analgesia pump. $0.075 \%$ ropivacaine injection $10 \mathrm{ml}, 0.5 \mu \mathrm{g} / \mathrm{ml}$ sulfentanyl injection $10 \mathrm{ml}$ in the experimental group, and $0.1 \%$ ropivacaine injection $10 \mathrm{ml}$, and $0.5 \mu \mathrm{g} / \mathrm{ml}$ sulfentanyl injection $100 \mathrm{ml}$ in the control group were injected into the epidural analgesia pump for anaesthesia. In both groups, the loading dose was $3 \mathrm{ml}$, the background infusion dose was $4 \mathrm{ml} / \mathrm{h}$, the single supplementary PCA dose was $2 \mathrm{ml} /$ time, and the locking time was $15 \mathrm{~min}$. Anaesthesia infusion was stopped at full opening of the uterus and epidural catheter was removed after the perineal stitch. Venous blood $2 \mathrm{ml}$ was taken at T1 (cervix open to $2 \mathrm{~cm}$ ), T2 (cervix fully open) and T3 (24 h postpartum) and the concentration of IL-6 TNF- $\alpha$ was detected by ELISA. All the operations were carried out strictly according to the instructions of the kit.

Observation index. Visual analogue score (VAS) of parturient pain, labor duration, analgesic time, febrile rate of parturient after administration at cervix open to $2 \mathrm{~cm}$, cervix open to $4 \mathrm{~cm}$, cervix fully open, and the concentration changes of IL- 6 and TNF- $\alpha$ in serum of parturient at T1, T2 and T3 were observed and compared. During epidural labor analgesia, the temperature of the parturient was measured and recorded once an hour until the end of labor. If body temperature was higher than $37.5^{\circ} \mathrm{C}$, it was considered febrile. VAS judging criteria (14): painless is 0 point, mild pain is $1-3$ points, moderate pain is $4-7$ points, and severe pain is $8-10$ points.

Statistical analysis. The statistical analysis was conducted by SPSS 15.0 [AsiaAnalytics (formerly SPSS China)] statistical software, and the measurement data were represented by mean \pm SD. Student's t-test was used for comparison between the two groups. Repeated analysis of variance was used at different time-points. Chi-square test was used for enumeration data. $\mathrm{P}<0.05$ was considered to indicate a statistically significant difference.

\section{Results}

Comparison of normal information between the two groups. There was no significant difference in age, body weight, 
Table I. Basic information.

\begin{tabular}{lcccr}
\hline Factors & Experimental group $\mathrm{n}=105$ & Control group $\mathrm{n}=93$ & $\mathrm{t}$ & $\mathrm{P}$-value \\
\hline Age & $25.9 \pm 1.7$ & $26.1 \pm 1.5$ & 0.873 & 0.384 \\
Body weight $(\mathrm{kg})$ & $60.3 \pm 2.9$ & $60.1 \pm 3.1$ & 0.469 & 0.640 \\
Height $(\mathrm{cm})$ & $160.2 \pm 4.2$ & $159.7 \pm 6.3$ & 0.664 & 0.508 \\
Gestational age (week) & $39.0 \pm 0.5$ & $38.9 \pm 0.6$ & 1.279 & 0.203 \\
Cervix dilatation degree (cm) & $1.9 \pm 0.4$ & $2.0 \pm 0.6$ & 1.394 & 0.165 \\
Blood loss (ml) & $249.35 \pm 78.14$ & $261.47 \pm 80.71$ & 1.073 & 0.285 \\
Complete blood count & & & & \\
Hemoglobin (g/l) & $98 \pm 22$ & $102 \pm 17$ & 1.418 & 0.158 \\
RBC (x1012/l) & $3.09 \pm 0.69$ & $3.11 \pm 1.04$ & 0.161 & 0.872 \\
Leucocyte count (x10/l) & $11.04 \pm 1.21$ & $10.91 \pm 1.26$ & 0.740 & 0.460 \\
Blood sugar (mmol/l) & $5.97 \pm 1.01$ & $6.22 \pm 0.98$ & 1.763 & 0.080 \\
\hline
\end{tabular}

Table II. Comparison of VAS scores between the two groups at different time-points.

\begin{tabular}{lcccr}
\hline Time & Experimental group n=105 & Control group $\mathrm{n}=93$ & $\mathrm{t}$ & P-value \\
\hline Cervix open to $2 \mathrm{~cm}$ & $7.2 \pm 1.3$ & $6.9 \pm 1.2$ & 1.680 & 0.095 \\
Cervix open to $4 \mathrm{~cm}$ & $4.1 \pm 1.5$ & $4.2 \pm 1.1$ & 0.529 & 0.597 \\
Cervix fully open & $1.9 \pm 0.4$ & $1.8 \pm 0.4$ & 1.756 & 0.081 \\
\hline
\end{tabular}

VAS, visual analogue score.

gestational age, blood loss and blood sugar between the two groups (Table I).

Comparison of VAS scores between the two groups at different time-points. The VAS scores were $7.2 \pm 1.3,4.1 \pm 1.5$ and $1.9 \pm 0.4$, respectively at cervix open to $2 \mathrm{~cm}$, cervix open to $4 \mathrm{~cm}$, cervix fully open in the experimental group, and the VAS scores were $6.9 \pm 1.2,4.2 \pm 1.1$ and $1.8 \pm 0.4$ in the control group. There was no significant difference in VAS score between the two groups ( $\mathrm{P}>0.05$; Table II).

Comparison of body temperature and febrile rate between two groups at different time points. Before analgesia and $1,2,3 \mathrm{~h}$ after analgesia, the temperature of parturients in both groups did not increase significantly and there was no significant difference in body temperature between the two groups $(\mathrm{P}<0.05)$. While the body temperature was significantly higher at 4 and $5 \mathrm{~h}$ after analgesia, parturition and $1 \mathrm{~h}$ postpartum than that before analgesia, and the body temperature in the control group was significantly higher than that in the experimental group at 4 and $5 \mathrm{~h}$ after analgesia $(\mathrm{P}<0.05)$. There were 21 febrile parturients in the experimental group, and the febrile rate was $20.00 \%$. There were 39 febrile parturients in the control group, and the febrile rate was $41.94 \%$. The febrile rate in the experimental group was significantly lower than that in the control group $(\mathrm{P}<0.05$; Table III).

Comparison of labor duration at different stages and analgesia time between the groups. There was no significant difference in the first and third stage of labor between the two groups $(\mathrm{P}>0.05)$. However, the second stage of labor and analgesic time in the experimental group were significantly shorter than those in the control group $(\mathrm{P}<0.05$; Table IV).

Concentration changes of IL- 6 and TNF- $\alpha$ in serum of parturient at T1, T2 and T3. There was no significant difference in IL- 6 and TNF- $\alpha$ between the two groups at T1 and T3 (P>0.05). However, IL-6 and TNF- $\alpha$ concentrations in the experimental group were significantly lower than those in the control group at T2 ( $<<0.05$; Figs. 1 and 2$)$.

\section{Discussion}

Labor pain is a complex, subjective, multidimensional response to sensory nerve stimulation during labor (15). For many parturients, labor analgesia not only alleviates the pain during delivery, but also reduces the stress and cesarean section rate of parturient. Therefore, an increasing number of parturients choose labor analgesia during delivery $(16,17)$. Epidural labor analgesia creates a good labor condition for parturients, but there are also some problems, among which fever in parturient due to epidural anaesthesia is a subject of great concern at present (18). Fever or even ardent fever during delivery may lead to intrauterine fetal death, neonatal septicemia and other problems (19). Therefore, clarifying the mechanism of epidural anesthesia in increasing maternal temperature and controlling the temperature rise of parturient by adjusting the way of administration and 
Table III. Comparison of body temperature and febrile rate between the two groups at different time-points.

\begin{tabular}{|c|c|c|c|c|}
\hline Time & Experimental group $n=105$ & Control group $n=93$ & $\mathrm{t} / \chi^{2}$ & P-value \\
\hline Before analgesia & $36.3 \pm 0.3$ & $36.4 \pm 0.3$ & 2.341 & 0.020 \\
\hline $1 \mathrm{~h}$ after analgesia & $36.6 \pm 0.3$ & $36.7 \pm 0.4$ & 2.004 & 0.047 \\
\hline $2 \mathrm{~h}$ after analgesia & $36.8 \pm 0.4$ & $36.7 \pm 0.5$ & 1.728 & 0.086 \\
\hline $3 \mathrm{~h}$ after analgesia & $36.8 \pm 0.6$ & $36.7 \pm 0.5$ & 1.265 & 0.208 \\
\hline $4 \mathrm{~h}$ after analgesia & $36.9 \pm 0.3^{\mathrm{a}}$ & $37.1 \pm 0.5^{\mathrm{a}}$ & 3.457 & $<0.001$ \\
\hline $5 \mathrm{~h}$ after analgesia & $37.0 \pm 0.5^{\mathrm{a}}$ & $37.3 \pm 0.6^{\mathrm{a}}$ & 3.836 & $<0.001$ \\
\hline At parturition & $37.0 \pm 0.6^{\mathrm{a}}$ & $37.1 \pm 0.6^{\mathrm{a}}$ & 1.170 & 0.243 \\
\hline $1 \mathrm{~h}$ postpartum & $36.9 \pm 0.7^{\mathrm{a}}$ & $37.0 \pm 0.6^{\mathrm{a}}$ & 1.072 & 0.285 \\
\hline Febrile rate $[\mathrm{n},(\%)]$ & $21(20.00)$ & $39(41.94)$ & 11.24 & $<0.001$ \\
\hline
\end{tabular}

${ }^{\mathrm{a}} \mathrm{P}<0.05$, body temperature was significantly higher than that before analgesia.

Table IV. Comparison of labor duration at different stages and analgesia time between two groups (min).

\begin{tabular}{lcrr}
\hline Factors & Experimental group n=105 & Control group n=93 & $\mathrm{t}$ \\
\hline First stage & $639.18 \pm 45.27$ & $634.31 \pm 43.41$ & 0.770 \\
Second stage & $52.75 \pm 1.66$ & $74.74 \pm 3.42$ & 58.57 \\
Third stage & $8.76 \pm 0.69$ & $8.51 \pm 0.85$ & $<0.442$ \\
Analgesic time & $169.72 \pm 14.98$ & $257.32 \pm 25.09$ & 0.001 \\
& & & 30.21 \\
\hline
\end{tabular}

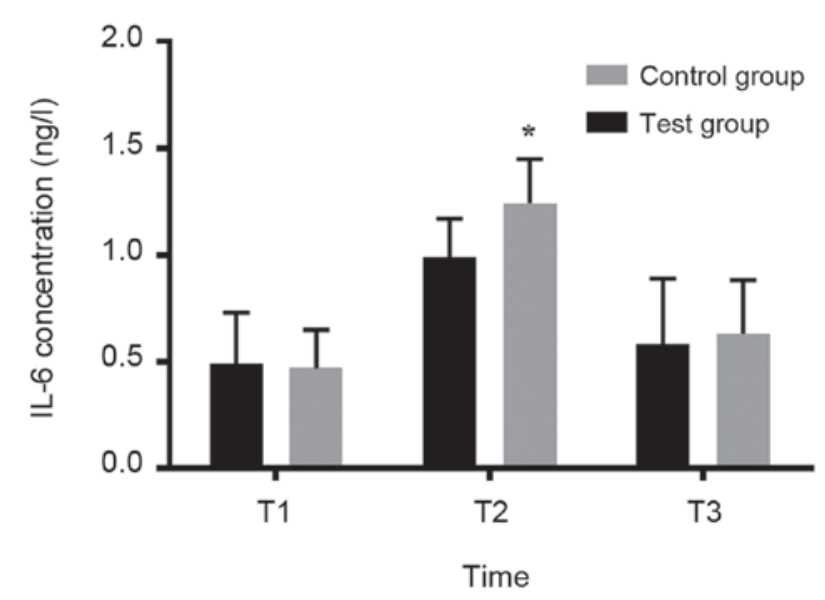

Figure 1. Concentration changes of IL-6 in serum at different time-points in the two groups (ng/l). There was no significant difference in IL-6 concentration between the experimental and control groups at T1 and T3 $(\mathrm{P}>0.05)$. However, IL-6 concentration in the experimental group was significantly lower than that in the control group at T2 $(\mathrm{P}<0.05)$. Concentration in the experimental group was significantly lower than that in the control group $\left({ }^{*} \mathrm{P}<0.05\right)$; IL-6, interleukin-6.

metering of anesthesia has become a hot research topic in recent years. IL-6 and TNF- $\alpha$ are important factors during parturition. The concentration of IL- 6 and TNF- $\alpha$ changes with the concentration change of epidural anesthetic, which affects maternal body temperature in a different degree (20). Observing the effect of ropivacaine at different concentrations on cell factor level in parturient with epidural labor analgesia is helpful to provide reference for clinical use of epidural labor analgesia.

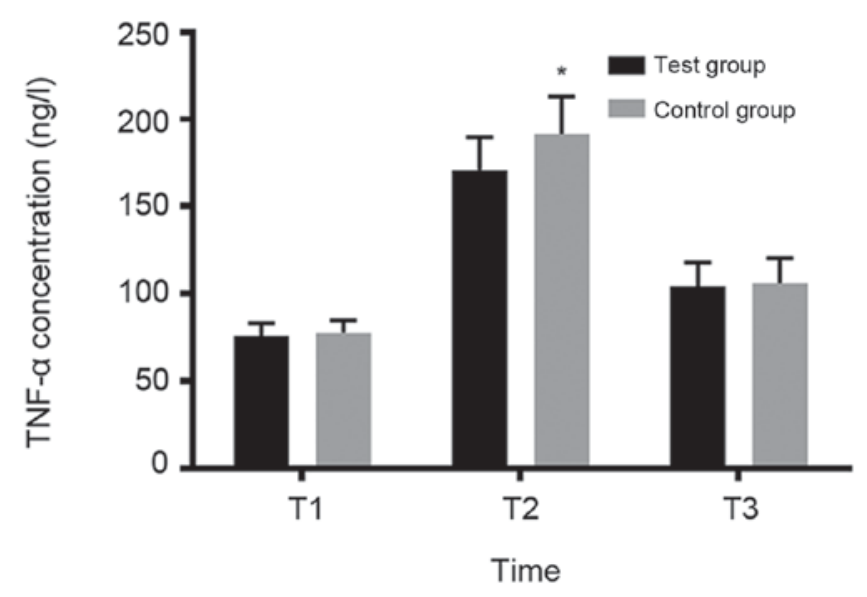

Figure 2. Concentration changes of TNF- $\alpha$ in serum at different time-points in the two groups (ng/l). There was no significant difference in TNF- $\alpha$ concentration between the experimental and control groups at T1 and T3 $(\mathrm{P}>0.05)$. However, TNF- $\alpha$ concentration in the experimental group was significantly lower than that in the control group at $\mathrm{T} 2(\mathrm{P}<0.05)$. Concentration in the experimental group was significantly lower than that in the control group $\left({ }^{*} \mathrm{P}<0.05\right)$, TNF- $\alpha$, tumor necrosis factor- $\alpha$.

In this study, it was found that there was no significant difference in VAS score between the experimental and control groups $(\mathrm{P}>0.05)$ at cervix open to $2 \mathrm{~cm}$, cervix open to $4 \mathrm{~cm}$ and cervix fully open, which indicated that there was no significant difference in the analgesic effect of parturients when ropivacaine concentration was 0.1 and $0.075 \%$, respectively. When comparing the body temperature and febrile rate of the groups at different time-points, it was found that before analgesia and at 1, 2, $3 \mathrm{~h}$ after analgesia, the temperature 
of parturients in both groups did not increase significantly and there was no significant difference in body temperature between the two groups $(\mathrm{P}>0.05)$. The body temperature significantly increased at 4 and $5 \mathrm{~h}$ after analgesia, parturition and $1 \mathrm{~h}$ postpartum, and the body temperature in the control group was significantly higher than that in the experimental group at 4 and $5 \mathrm{~h}$ after analgesia $(\mathrm{P}<0.05)$. There were 21 febrile parturients in the experimental group, and the febrile rate was $20.00 \%$. There were 39 febrile parturients in the control group, and the febrile rate was $41.94 \%$. The febrile rate in the experimental group was significantly lower than that in the control group $(\mathrm{P}<0.05)$. The results indicated that the increase in body temperature and febrile rate of epidural labor analgesia with $0.075 \%$ ropivacaine combined with sulfentanyl were smaller than that with $0.1 \%$ ropivacaine, which was consistent with the results of Gogarten et al (21). The comparison of labor duration at different stages and analgesia time showed that the duration of the first and third stages of labor was the same, and there was no significant difference between the two groups $(\mathrm{P}>0.05)$. However, the second stage of labor and analgesic time in the experimental group were significantly shorter than those in the control group $(\mathrm{P}<0.05)$. Studies have also shown that epidural anesthesia with $0.075 \%$ ropivacaine combined with sulfentanyl could not only achieve a good analgesic effect, but also result in a shorter second stage of labor $(22,23)$. The reason is that the concentration of ropivacaine is positively correlated with the time of analgesia, and the effect of low dose of anaesthesia on uterine contraction is small. IL-6, as the main pro-inflammatory cytokine, has been used as a marker of perioperative inflammatory response in many studies. TNF- $\alpha$, as an inflammatory cytokine closely related to the pain acceleration, can cause late immunologic injury $(4,24)$. The concentration changes of IL- 6 and TNF- $\alpha$ levels in serum of parturients at T1, T2 and T3 were evaluated in this study. The result showed that there was no significant difference in IL- 6 and TNF- $\alpha$ concentration between the two groups at T1 and T3 (P>0.05). However, the IL-6 and TNF- $\alpha$ concentrations in the experimental group were significantly lower than those in the control group at $\mathrm{T} 2(\mathrm{P}<0.05)$. This suggested that the use of $0.075 \%$ ropivacaine contributed to inflammation $<0.1 \%$ ropivacaine.

In conclusion, the effect of patient-controlled epidural administration with $0.075 \%$ ropivacaine injection combined with $0.5 \mathrm{mg} / \mathrm{ml}$ sulfentanyl injection on labor analgesia is shorter than that with $0.1 \%$ ropivacaine combined with sulfentanyl. It can also result in a shorter second stage of labor and analgesia time, lower intrapartum febrile rate, and contributed to inflammation $<0.1 \%$ ropivacaine combined with sulfentanyl. However, labor itself is a complex process, and is affected by many factors. We mainly studied the influence of the preliminary test of anesthesia record on labor, so we did not record the auxiliary anesthesia dosage used by the labor in the experiment, which is also a negligence of this study. Therefore, the way and dosage of labor analgesia in clinical application need to be further explored and studied.

\section{Acknowledgements}

Not applicable.

\section{Funding}

No funding was received.

\section{Availability of data and materials}

The datasets used and/or analyzed during the current study are available from the corresponding author on reasonable request.

\section{Authors' contributions}

$\mathrm{XZ}$ and JL recorded and analyzed the general information of patients. SD was responsible for upper fetal heart monitoring and ECG monitoring. ZX and ZL contributed to observation index analysis. All authors have read and approved the final manuscript.

\section{Ethics approval and consent to participate}

The study was approved by the Ethics Committee of Shanghai First Maternity and Infant Hospital, Tongji University School of Medicine (Shanghai, China) and written informed consents were signed by the patients.

\section{Patient consent for publication}

Not applicable.

\section{Competing interests}

The authors declare that they have no competing interests.

\section{References}

1. He ZY, Jiao QL, Miao Y and Sun Y: Clinical observation of ropivacaine compuled with sufentanil for painless childbirth. Pak J Pharm Sci 29 (Suppl 2): 707-709, 2016.

2. Palm S, Gertzen W, Ledowski T, Gleim M and Wulf H: Minimum local analgesic dose of plain ropivacaine vs. ropivacaine combined with sufentanil during epidural analgesia for labour. Anaesthesia 56: 526-529, 2001.

3. Kampe S, Tausch B, Paul M, Kasper SM, Bauer K, Diefenbach C and Kiencke P: Epidural block with ropivacaine and bupivacaine for elective caesarean section: maternal cardiovascular parameters, comfort and neonatal well-being. Curr Med Res Opin 20: 7-12, 2004

4. Purdy M, Kokki M, Anttila M, Aspinen S, Juvonen P, Korhonen R, Selander T, Kokki H and Eskelinen M: Does the rectus sheath block analgesia reduce the inflammatory response biomarkers IL-1ra, IL-6, IL-8, IL-10 and IL- $1 \beta$ concentrations following surgery? A randomized clinical trial of patients with cancer and benign disease. Anticancer Res 36: 3005-3011, 2016.

5. Camorcia M and Capogna G: Epidural levobupivacaine, ropivacaine and bupivacaine in combination with sufentanil in early labour: a randomized trial. Eur J Anaesthesiol 20: 636-639, 2003.

6. Feng SW, Xu SQ, Ma L, Li CJ, Wang X, Yuan HM, Wang FZ, Shen XF and Ding ZN: Regular intermittent bolus provides similar incidence of maternal fever compared with continuous infusion during epidural labor analgesia. Saudi Med J 35: 1237-1242, 2014.

7. Saito M, Okutomi T, Kanai Y, Mochizuki J, Tani A, Amano K and Hoka S: Patient-controlled epidural analgesia during labor using ropivacaine and fentanyl provides better maternal satisfaction with less local anesthetic requirement. J Anesth 19: 208-212, 2005

8. Wang X, Xu S, Qin X, Li X, Feng SW, Liu Y, Wang W, Guo X, Shen $\mathrm{R}$, Shen $\mathrm{X}$, et al: Comparison between the use of ropivacaine alone and ropivacaine with sufentanil in epidural labor analgesia. Medicine (Baltimore) 94: e1882, 2015. 
9. Schulpis KH, Vlachos GD, Karikas GA, Papakonstantinou ED, Vlachos DG, Papassotiriou I, Antsaklis A and Tsakiris S: The effect of the mode of delivery on maternal-neonatal interleukin-6, biogenic amine and their precursor amino acid concentrations. Clin Chem Lab Med 46: 1624-1630, 2008.

10. Dunn AB, Paul S, Ware LZ and Corwin EJ: Perineal injury during childbirth increases risk of postpartum depressive symptoms and inflammatory markers. J Midwifery Womens Health 60: 428-436, 2015.

11. Prusty BK, Hedau S, Singh A, Kar P and Das BC: Selective suppression of NF-kBp65 in hepatitis virus-infected pregnant women manifesting severe liver damage and high mortality. Mol Med 13: 518-526, 2007.

12. Williams M: The combined spinal-epidural technique for the provision of analgesia in obstetric anaesthesia. Anaesthesia 56: 500, 2001.

13. Goetzl L: Epidural analgesia and maternal fever: A clinical and research update. Curr Opin Anaesthesiol 25: 292-299, 2012.

14. Liu D, He X, Zheng W, Zhang Y, Li D, Wang W, Li J and Xu W: Translation and validation of the simplified Chinese new Knee Society Scoring System. BMC Musculoskelet Disord 16: 391, 2015.

15. Abushaikha LA: Methods of coping with labor pain used by Jordanian women. J Transcult Nurs 18: 35-40, 2007.

16. Kuczkowski KM: Labor analgesia for the parturient with herbal medicines use: What does an obstetrician need to know? Arch Gynecol Obstet 274: 233-239, 2006.

17. Sharma SK, McIntire DD, Wiley J and Leveno KJ: Labor analgesia and cesarean delivery: an individual patient meta-analysis of nulliparous women. Anesthesiology 100: 142-148, discussion 6A, 2004.

18. Yoon HJ, Do SH and Yun YJ: Comparing epidural surgical anesthesia and spinal anesthesia following epidural labor analgesia for intrapartum cesarean section: A prospective randomized controlled trial. Korean J Anesthesiol 70: 412-419, 2017.
19. Kokki H, Ruuskanen A and Karvinen M: Comparison of epidural pain treatment with sufentanil-ropivacaine infusion with and without epinephrine in children. Acta Anaesthesiol Scand 46: 647-653, 2002.

20. Mantha VR, Vallejo MC, Ramesh V, Jones BL and Ramanathan S: Maternal and cord serum cytokine changes with continuous and intermittent labor epidural analgesia: a randomized study. ScientificWorldJournal 2012: 607938, 2012.

21. Gogarten W, Van de Velde M, Soetens F, Van Aken H, Brodner G, Gramke HF, Soetens M and Marcus MA: A multicentre trial comparing different concentrations of ropivacaine plus sufentanil with bupivacaine plus sufentanil for patient-controlled epidural analgesia in labour. Eur J Anaesthesiol 21: 38-45, 2004

22. Boulier V, Gomis P, Lautner C, Visseaux H, Palot M and Malinovsky JM: Minimum local analgesic concentrations of ropivacaine and levobupivacaine with sufentanil for epidural analgesia in labour. Int J Obstet Anesth 18: 226-230, 2009.

23. Yue HL, Shao LJ, Li J, Wang YN, Wang L and Han RQ: Effect of epidural analgesia with $0.075 \%$ ropivacaine versus $0.1 \%$ ropivacaine on the maternal temperature during labor: A randomized controlled study. Chin Med J (Engl) 126: 4301-4305, 2013.

24. Zhao Y, Wang W, Wu X, Ma X, Qu R, Chen X, Liu C, Liu Y, Wang X, Yan P, et al: Mangiferin antagonizes TNF- $\alpha$-mediated inflammatory reaction and protects against dermatitis in a mice model. Int Immunopharmacol 45: 174-179, 2017.

This work is licensed under a Creative Commons Attribution-NonCommercial-NoDerivatives 4.0 International (CC BY-NC-ND 4.0) License. 